\title{
NARRATIVAS DE IDENTIDAD NACIONAL Y POLÍTICAS DE EXCLUSIÓN / INCLUSIÓN DE AFRODESCENDIENTES Y AFRICANOS EN ARGENTINA
}

\author{
Narratives of National Identity and Exclusion / Inclusion Policies of Africans \\ and Afro-descendants in Argentina
} MARTINA GARCÍA*

Fecha de recepción: 03 de agosto de 2017 - Fecha de aprobación: 28 de septiembre de 2017

\section{Resumen}

La presencia africana en Argentina es vasta, tanto por su antigüedad (sus orígenes se remontan a fines del siglo XVI) como por su variedad y riqueza de procedencias (actualmente, se compone de tres grandes grupos de población: africanos, afrodescendientes y afroargentinos). No obstante, dicha presencia ha permanecido oculta hasta hace pocas décadas. Sólo en los últimos años, particularmente a partir de 2005, la narrativa de identidad nacional dominante sobre la cual pudo montarse el silenciamiento del linaje afro local, presenta indicios de estar siendo revisada. El presente trabajo se propone describir las características de este proceso y ponderar su alcance. Para ello, previamente se analiza el modo que asumió el ocultamiento histórico de la presencia africana, lo que supone contextualizarla dentro del mapa de las identidades étnicoraciales de la Argentina. Hacia el final del artículo se reflexiona acerca de las consecuencias de un novedoso relato nacional sobre la africanidad y sus posibles aportes para el estudio de las identidades y el racismo. El trabajo se basa en tres tipos de registro: histórico, documental y etnográfico.

Palabras clave: afrodescendientes, africanos, Argentina, Estado-nación, identidad

\section{Abstract}

The African presence in Argentina is vast, not just due to its antiquity (begins at the end of the 16th century), but also due to the diversity of origins (nowadays, it is composed by africans, afro-descendants and afro-argentines). Nevertheless, this presence has remained hidden throughout the years. Only in the last period, especially since 2005, it begins to show recognition of its existence. In this paper, I analyze this process and its implications for the study of identities and racism. Previously, I describe the historical process that made possible the concealment of the African presence, within the context of the ethnic-racial identities map of Argentina. These results have been obtained through three types of sources: historical, documentary and ethnographic.

Keywords: afro-descendants, africans, Argentina, nation-state, identity

* Dra. en Antropología Social. Docente Universidad Nacional de Luján - Universidad de Buenos Aires, Buenos Aires, Argentina. Artículo enmarcado en tesis doctoral en Antropología Social. Correo-e: martinainesgarcia@gmail.com 
La presencia africana en Argentina es vasta, tanto por su antigüedad como por su variedad y riqueza de procedencias. Ésta se remonta a las últimas décadas del siglo XVI, cuando hizo su primer arribo un contingente de esclavos a la región del Río de la Plata. Así se inicia el primer contacto poblacional entre África y lo que hoy es Argentina. De ahí en adelante, en un flujo casi ininterrumpido, aunque variable en intensidad y procedencias, distintas corrientes migratorias africanas enriquecerán con sus aportes a la población local. A continuación, repasaremos brevemente estos procesos.

\section{Presencia africana en Argentina}

Entre los siglos XVI y XIX, la llegada de africanos a la región del Río de la Plata se da en el marco del denominado comercio triangular, una ruta comercial en tres etapas y entre tres continentes sobre la cual se estableció el siguiente circuito de circulación de mercancías: 1) mano de obra esclavizada, desde la región subsahariana de África que da al Océano Atlántico hacia América -en un principio, América del Sur y, más tardíamente, América del Norte y el Caribe, 2) productos como azúcar, tabaco, café, algodón, cacao y metales preciosos, producidos en América y comercializados en Europa y 3) manufacturas, confeccionadas en Europa y vendidas en los dos puntos restantes del circuito. En ese contexto, un número significativo de africanos, principalmente varones, fueron traidos como esclavos para ser vendidos en el mercado local ${ }^{1}$.

Solo entre 1740 y 1810 ingresaron por el Río de la Plata más de 45.000 africanos esclavizados (Guzmán, 2006). Se calcula que hacia el año 1810 , la población africana representaba el $33 \%$ del total de los habitantes de Buenos Aires y se estiman cifras mayores para otras provincias: $64 \%$ en Tucumán, $54 \%$ en Santiago del Estero, $52 \%$ en Catamarca y $46 \%$ en Salta (Guzmán, 2006, pp. 6-7), proporcionalidad que fue variando a lo largo de los años, de acuerdo a la importancia económica de cada una de las regiones ${ }^{2}$.

Poco se sabe acerca de estos primeros contingentes de africanos. Esto se debe, en parte, a que los sistemas de clasificación poblacional utilizados en la colonia (censos, expedientes judiciales, documentos de escribanías, actas de nacimiento, matrimonio y defunción) no eran exhaustivos y variaban por época y por región. A su vez, siendo el mestizaje entre africanos y nativos por demás frecuente, los hijos de estas uniones se registraban indistintamente dentro de las "castas naturales" (indígenas) o dentro de la "población de color" (de linaje afro). Es decir como mulatos, pardos, zambos, mestizos o cholos. Existen registros de asociaciones que evidencian situaciones de sincretismo religioso y cultural afro-católico ya en el siglo XVII. Estas se conocen como cofradías y, más tardíamente, como naciones (Morini, 2001; Gomes, 2001).

La trata esclavista fue disminuyendo lentamente a lo largo del siglo XIX. En el año 1813 se declaró la "libertad de vientres" por la cual los hijos e hijas de esclavas serían considerados/ as libres. Fue recién en 1853 cuando la esclavitud quedó constitucionalmente abolida en el Río de la Plata, pero se sabe que la abolición real, en muchos casos, se concretó años más tarde.

En el momento en que el ingreso de africanos esclavizados estaba concluyendo, comenzó una nueva dinámica inmigratoria desde África hacia la Argentina, esta vez procedente de las islas de Cabo Verde. Con intensidad variable y algunas 
interrupciones -por ejemplo, entre 1914 y 1918-, esta corriente se inicia a fines del siglo XIX extendiéndose hasta fines de los años '60 del siglo XX. Quienes llegaron fueron principalmente jóvenes de entre 20 y 35 años, de ambos sexos, que decidieron emigrar escapando del hambre y la precariedad socioeconómica generalizada imperante en Cabo Verde en tiempos de la administración colonial portuguesa ${ }^{3}$. Los varones llegaron en barcos en los que trabajaban como tripulación, como polizones o pasajeros. Las mujeres, como pasajeras. En todos los casos, es difícil precisar su número puesto que, por haber ingresado a la Argentina con pasaporte portugués, fueron incluidos en las Memorias de Inmigración como portugueses (Otero, 2000). Aún más difícil es conocer el número de los que ingresaron al país clandestinamente.

En Argentina, los caboverdeanos se instalaron en las zonas portuarias (especialmente, en Dock Sud, Ensenada y La Boca y, en menor medida, en Mar del Plata y Bahía Blanca). Y mientras que los varones trabajaron en tareas vinculadas a la navegación, las mujeres se dedicaron al servicio doméstico. En términos generales, puede decirse que esta fue una migración en cadena, estructurada sobre "lazos de familia" (Maffia, 2010, p. 223) $^{4}$.

Al igual que otros colectivos de inmigrantes de la época, los caboverdeanos fundaron distintas asociaciones de ayuda mutua. En un primer momento, estas perseguían objetivos de ayuda solidaria para sus miembros, en un contexto general de gran precariedad socioeconómica. Pero con el transcurso de los años, esos objetivos fueron ampliándose a la reafirmación de la cultura e identidad caboverdeanas, la promoción de los derechos humanos y la lucha contra la discriminación.
Los procesos identitarios de los caboverdeanos en Argentina resultan relevantes en función de las cuestiones que trataremos más adelante en este artículo. Ya en la sociedad de origen, Cabo Verde había sido construida como una nación portuguesa, alejada de África y, durante mucho tiempo, los caboverdeanos en Argentina replicaron este modelo, en un contexto igualmente favorable a la europeización. Solo recientemente, los migrantes caboverdeanos y sus descendientes comenzaron a argentinizarse, incluso algunos comienzan a identificarse con un origen africano (Maffia \& Ceirano, 2007; Otero, 2000; Contarino, 2012). Esta identificación como argentinos y afrodescendientes es común sobre todo en los jóvenes y se registra a partir de la década del '90, en un contexto de aparición de nuevos migrantes africanos en el país.

Desde los años '90 y hasta la actualidad, la Argentina recibe un pequeño flujo de migrantes africanos de variadas procedencias nacionales, posicionándose junto con Brasil como el país con el mayor número de habitantes africanos de la región sudamericana (Marcelino \& Cerrutti, 2011). La elección de estos destinos generalmente se explica por las crecientes trabas impuestas a la inmigración en los países centrales. No obstante, hay que aclarar que un porcentaje pequeño pero difícil de determinar ha llegado a la región de manera fortuita, luego de haber viajado como polizón en un barco que terminó anclando en costas sudamericanas ${ }^{5}$.

Por tratarse de migraciones recientes y de baja incidencia numérica, esta población no ha despertado mayor interés dentro del Estado y, hasta hace pocos años, tampoco lo había hecho en el ámbito de las ciencias sociales. Es por ello que no existen relevamientos específicos deta- 
llados. Según los datos del último Censo Nacional de Población, Hogares y Vivienda realizado en 2010, la población nacida en países africanos suma un total de 2.738 personas, cifra que representa el $0,15 \%$ del total de habitantes de origen extranjero. Dentro de ese total, la población masculina duplica a la femenina con 1.825 casos. La mayoría proviene de la región subsahariana, también denominada el África negra.

Entre los principales países de procedencia se destacan Senegal con 459 individuos, Sudáfrica con 406, Egipto con 274, Marruecos con 231, Argelia con 210, Nigeria con 160, Ghana con 99, Angola con 81 y Cabo Verde con 69 (Fuente: Censo Nacional de Población, Hogares y Viviendas 2010, base de datos Redatam). Existen otros registros que arrojan cifras mucho mayores, sobre todo en el caso de los senegaleses quienes son hoy el colectivo nacional mayoritario dentro de los africanos ${ }^{6}$. Muchos de estos migrantes tienen una pareja argentina o han tenido hijos en este país, lo que les permite tener una nacionalidad argentina (a ellos, por el principio de ius sanguinis y a sus hijos, por el principio de ius solis).

Su modo de subsistencia más frecuente es a través de la venta callejera de productos de bijouterie y accesorios como relojes, cinturones y billeteras. Dicha tarea, a veces se realiza en puestos fijos y otras, mediante una circulación constante -sobre todo por bares y restaurantescon pequeños maletines. En correlato con los datos estadísticos generales, la mayor parte de los vendedores ambulantes africanos son senegaleses, pero la ocupación es ejercida también por oriundos de las otras nacionalidades. La venta ambulante es común también en el África subsahariana (Mitullah, 2003) y en Argentina es, sin duda, una de las pocas opciones laborales disponibles para los africanos.
Al igual que los anteriores, los migrantes africanos recientes han conformado distintas estructuras asociativas. En algunos casos identificados por su pertenencia nacional, o bien, referenciados en categorías más globales (como subsaharianos, como francófonos o como parte de una diáspora). En coincidencia con la distribución residencial general que ubica a la mayoría de los habitantes africanos en Buenos Aires, la mayor parte de las organizaciones se registran en esta área ${ }^{7}$. Sin embargo, hay registros de asociaciones también en otras provincias $^{8}$. Además, existen asociaciones en las que convergen migrantes africanos y afrodescendientes de diversas nacionalidades identificados como parte de una diáspora ${ }^{9}$.

A las tres fuentes de formación del colectivo afro local mencionadas hasta aquí, podría sumarse un cuarto registro -más impreciso desde el punto de vista numérico y temporal- en el que se ubican los migrantes afrodescendientes procedentes de otros países de Latinoamérica entre los que se destacan Uruguay, Haití, Cuba y República Dominicana. En todos los casos, con números relativamente pequeños.

Como puede verse, la presencia africana en Argentina es vasta, tanto por su riqueza identitaria y cultural (por abarcar comunidades varias y de distintas procedencias) como por su antigüedad (los registros nos remontan varios siglos atrás). No obstante, dicha presencia ha sido sistemáticamente silenciada, al punto que hacia fines del siglo XIX parecía evidente que los negros habían desaparecido por completo. Esta afirmación se sostenía en una serie de factores: las sucesivas campañas militares que tuvieron lugar a lo largo del siglo XIX en las que la población negra masculina fue sistemáticamente reclutada, el mestizaje, la combinación 
entre altas tasas de mortalidad y bajas tasas de natalidad (producto de la precariedad socioeconómica que afectó particularmente a este grupo) y la paulatina declinación del comercio de esclavos a partir de su abolición oficial en 1813 (Rodríguez Molas, 1962; Goldberg, 1995).

Investigaciones posteriores observaron, a su vez, otras causales de la desaparición afrodescendiente resumibles bajo la idea de invisibilización (Andrews, 1990; Guzmán, 2006, 2013; Geler, 2006, 2010; Frigerio, 2006). Sea a través de su borramiento de los registros estadísticos oficiales (por ejemplo, censos o actas de nacimiento, matrimonio y muerte), sea por medio de procesos de movilidad e integración social, paulatinamente los afrodescendientes dejaron de ser una identidad socialmente relevante dentro de la sociedad argentina. Según este registro, su desaparición se debe menos a un proceso de extinción que a un sistemático silenciamiento social. Pero ¿qué se iluminaba al silenciar dicha presencia? En el próximo apartado responderemos a esta pregunta.

\section{Narrativas de identidad nacional}

\section{Políticas de europeización y exclusión de la presencia africana}

A lo largo del siglo XIX, la población de ascendencia africana (al igual que la americana) quedó confinada fuera de los márgenes de la nación y, en su reemplazo, se edificó una narrativa de nacionalidad basada en un linaje europeo, posibilitada a través de la promoción planificada de la inmigración de ese origen ${ }^{10}$. Así, en el momento mismo de consolidación del Estado-nación argentino, se ponía en marcha una operación adicional a la de otros contextos nacionales: se importaba a un(os) otro(s) para volverlo(s) nosotros.

Esta operación encuentra su origen de la mano de la intelectualidad local hegemónica de ese siglo que, a lo largo de su segunda mitad, fue haciendo del Estado una maquinaria orientada al reemplazo sistemático de buena parte de su población. El ejemplo argentino se presenta como un caso en que "el Estado precede y, de alguna manera, construye la sociedad civil" (Villavicencio, 2003, p. 17). Aquí -en una clara diferencia con otros procesos- el Estado no se montará sobre una entidad preexistente (Briones, 2002, p. 68) sino que creará algo radicalmente nuevo. A modo de ejemplo, podemos citar las palabras de Domingo Faustino Sarmiento, uno de los arquitectos de la nación, quien en 1855 no dudaba en afirmar: "ningún rasgo apetecible tenemos de carácter nacional, ni en moral, ni en instituciones, ni en prácticas gubernativas, ni en tradiciones, ni en costumbres sino son las de la barbarie", por lo que llamaba a crear la nación "por decreto" (citado en Tonello, 1992, p. 5).

El fomento de la inmigración europea constituyó un verdadero asunto de Estado, y basta mirar las estadísticas de las décadas siguientes para advertir que este proyecto fue un éxito desde el punto de vista de los fines que perseguía. Cabe aclarar que no solo fueron las políticas estatales de atracción de inmigrantes las que tuvieron este efecto, otros factores (tales como la gran crisis agraria europea de fines del siglo XIX, la guerra franco-prusiana y la expansión económica argentina per se) operaron en favor del poblamiento inmigratorio de la Argentina. El hecho es que, para el año 1914 se registra un $27,3 \%$ de inmigrantes ultramarinos dentro de la población total del país y casi un $30 \%$ de 
población extranjera sumando a los inmigrantes limítrofes (Devoto, 2003).

Aunque la ideología proinmigratoria se encontraba ya presente en el temprano siglo XIX (Halperin, 1987), es evidente que hacia fines de ese siglo cobrará otra encarnadura. La llamada Ley de Inmigración y Colonización de 1876 resulta por demás elocuente. Por medio de la misma se creaba por ejemplo el Departamento General de Inmigración que, entre sus funciones, establecía "propender por todos los medios a su alcance a fomentar y facilitar la internación de los inmigrantes en el interior del país" y "proveer por cuenta de la Nación, el embarco y transporte de los inmigrantes que quieran internarse" (Primera Parte, Cap. I, Art. 2 extraído de Auza, 1970, p. 158), y fijaba como atributos del Poder Ejecutivo "nombrar agentes especiales en todos aquellos puntos de Europa o de América que considerase convenientes, con el encargo de fomentar la inmigración para la República Argentina" (Primera Parte, Capítulo II, Art. 4 extraído de Auza, 1970, p. 159). Mediante estos mecanismos y otros similares (posesión de las tierras sin costo alguno a cambio de su ocupación efectiva y explotación, exenciones impositivas, costeo de gastos de instalación, etc.) se buscaba hacer de la Argentina una nación de progreso.

La consolidación de la Argentina como una nación blanca y europea puede analizarse siguiendo varias líneas: la instauración de un modelo económico, la necesidad de unificación territorial y la expansión de las fronteras nacionales son algunas de ellas. Pero ¿cómo se sustenta la preferencia por la inmigración de ultramar? Porque, aunque resulta comprensible la pretensión de contar con abundancia de mano de obra en el marco de un proceso de unificación territorial y expansión de la frontera agropecuaria, estos hechos en sí mismos no explican esa preferencia. En efecto, como representantes del pensamiento evolucionista de la época, los miembros de las elites locales reprodujeron ese esquema que encuentra a Europa a la cabeza y, mediante un razonamiento semejante al de las formas de antropofagia positiva (Lévi-Strauss, 1976), recurrieron a la importación de europeos como fórmula para incorporar la civilización.

\section{Visibilización de la presencia africana y políticas de inclusión contemporáneas}

En las últimas décadas, -a la luz de las migraciones africanas más recientes, por un lado, y de un cierto revisionismo histórico dinamizado tanto por colectivos de la sociedad civil, académicos y agencias del Estado, por el otro- la presencia africana en Argentina dejó de ser un tema tabú. Este hecho se torna particularmente palpable a partir de 2005, cuando el Estado empieza a ocuparse de "lo afro" con sistematicidad $^{11}$. Desde entonces, se observan dos procesos sostenidos y novedosos: por un lado, un cierto número de iniciativas que apuntan a la exposición y difusión públicas de las temáticas afro y, por el otro, la creación y dinamización de agencias estatales que tienen entre sus funciones idear y poner en práctica estrategias para la inclusión de los afrodescendientes y africanos. Brindaremos un panorama general de cada dinámica para luego reflexionar sobre sus consecuencias. Esta tarea resume algunos resultados obtenidos en base al trabajo de campo realizado entre los años 2007 y 2015 en la Ciudad de Buenos Aires, combinando las técnicas de tradición antropológica (obser- 
vación participante y entrevistas semiabiertas) con otras de las ciencias sociales en general (observaciones sin participación, análisis de documentos y material audiovisual en diversos formatos, revisión de leyes y normativas, etc.).

Con referencia al primer proceso mencionado, a los fines expositivos, se construyeron los siguientes ejes que resumen y ordenan el relevamiento realizado durante todos estos años:

- Lucha contra la discriminación y el racismo: distintas acciones de reflexión y concientización en forma de talleres organizados por afroargentinos y/o académicos, canciones y materiales de lectura que problematizan (desnaturalizan) las formas de exclusión e inferiorización de los afrodescendientes.

- Diagnóstico: puesto que los afrodescendientes han sido históricamente ignorados y muy poco se sabe de ellos, distintas iniciativas se han propuesto explorar su importancia real en la sociedad argentina, realizando descripciones cuantitativas y/o cualitativas de distinto alcance sobre estos grupos. La iniciativa más relevante en este sentido ha sido la inclusión de una pregunta por la afrodescendencia en el último censo nacional de población realizado en $2010^{12}$.

- Revisiones del pasado: iniciativas que apuntan a repensar la historia nacional, regional, continental $y / 0$ intercontinental recuperando, en cada caso, la relación con el continente africano (desde el legado africano en la región en tiempos de la trata esclavista hasta la discursividad escolar sobre la historia argentina y el rol de los negros en el forjamiento de la independencia nacional).
- Conmemoraciones y homenajes: ya sea acciones puntuales (por ejemplo, celebratorias de las independencias africanas o recordatorias de personalidades afroargentinas) o bien, en el caso de las impulsadas desde el Estado, declaraciones de leyes (por ejemplo, la Ley nacional № 26.852 sancionada en 2013 que fija el 8 de noviembre como el Día Nacional de las/los Afroargentinas/os y de la Cultura Afro) ${ }^{13}$.

- Valorización cultural: muestras artísticas para difundir y jerarquizar la danza y expresiones musicales de raíz afro (varias de ellas, se organizaron en conjunto con la embajada de Brasil). También se realizaron talleres de formación en estas artes y jornadas de reflexión sobre religiosidad afro.

- Promoción de la identidad diaspórica: propuestas tendientes a propiciar una adscripción compartida sobre la base de un pasado en común que se remonta a la trata esclavista. Aludiendo a la idea de diáspora, se resalta dicha historia por sobre otras cualidades que diferenciarían a los participantes (por ejemplo, sus pertenencias nacionales o el color de la piel).

- Acciones afirmativas y de empoderamiento: con el objetivo de fortalecer al colectivo afrodescendiente, desde el Estado se lleva a cabo un relevamiento de organizaciones de mujeres afro con la finalidad de brindar luego cursos de capacitación y acompañamiento técnico para dichas organizaciones. Por otra parte, surgen iniciativas de autoafirmación dentro del propio colectivo (por ejemplo, el lanzamiento del periódico El Afroargentino o la puesta en escena de una obra teatral escrita y actuada por dos 
afroargentinas descendientes de africanos esclavizados y dirigida por una afrocubana. Dicha obra cuenta (saca a la luz) la historia afroargentina).

- Educación: acciones tendientes a intervenir en contextos educativos, recuperando el lugar y los aportes de la población de ascendencia africana en el pasado y presente de la sociedad argentina. Algunas fueron pensadas para los ámbitos de la educación formal y otras, para generar soportes y recursos orientados a la enseñanza fuera de la escuela. Dentro del primer caso, mencionamos como ejemplo una iniciativa de revisión de los manuales escolares de nivel primario en un acuerdo entre el Ministerio de Educación de la Nación y las principales editoriales. Dentro de las segundas, el lanzamiento de un dibujo animado que tiene como una de sus protagonistas a una niña negra, hija de padre esclavo y madre liberta donde se relata, con un enfoque novedoso e intercultural, la historia nacional.

Las acciones mencionadas tienen diversos orígenes, no necesariamente ligados a la iniciativa del Estado. Sin embargo, existe una agencia estatal que ha tenido un papel relevante en varias de ellas: el Instituto Nacional contra la Discriminación, la Xenofobia y el Racismo $\left(\right.$ INADI ${ }^{14}$. En lo que sigue sintetizamos su incidencia sobre "lo afro", iniciando así la descripción del segundo proceso señalado al inicio de este apartado.

Aunque fue creado en $1995^{15}$, recién a partir del lanzamiento de un Plan Nacional contra la Discriminación ${ }^{16}$, en 2005, el INADI encara un trabajo sistemático en el área y se convierte en el principal gestor estatal de los temas afro.
Este trabajo se formaliza por primera vez en 2006, cuando el organismo impulsa la formación de lo que denomina Foros de la Sociedad Civil, es decir, espacios abiertos a la participación de grupos vulnerados en sus derechos, orientados a monitorear, diseñar, cogestionar e impulsar iniciativas propias y ajenas que tiendan a revertir las condiciones de vulnerabilidad de esos grupos. En ese marco, se convoca a la comunidad afro a formar parte de un Consejo Asesor de la Sociedad Civil, y hacia fines de ese año, se crea el denominado Foro de Afrodescendientes de la Sociedad Civil. Varias de las iniciativas de visibilización mencionadas han surgido de este espacio o contaron con su intervención ${ }^{17}$.

La actuación del INADI ha tendido principalmente a revisar la historia nacional en su vinculación con África, reflexionar acerca de las características que asume el racismo en Argentina y rescatar la cultura afro en sus expresiones artísticas y religiosas. Estos frentes de acción tienen una relevancia particular para los afroargentinos y, de hecho, son ellos quienes mayor acercamiento han tenido a este organismo. Por otra parte, otras agencias cobran importancia para los africanos.

En los últimos años, agencias estatales destinadas a la población de origen extranjero y vinculadas con el sistema de asilo han funcionado como facilitadoras de la inclusión (parcial) de los migrantes de nacionalidades africanas. Algunas se crearon recientemente mientras que otras cuentan con una trayectoria de varias décadas. En todos los casos, nos referimos a espacios cuyo ingreso es voluntario ${ }^{18}$ y que tienen un doble rol: por un lado, son generadores de políticas o estrategias inclusivas y de integración y, por el otro, apuntan al cumpli- 
miento efectivo de derechos, en muchos casos, oficiando de fiscalizadores de otras agencias del Estado ${ }^{19}$.

En 2012, la Comisión para la Asistencia Integral y Protección del Refugiado y Peticionante de Refugio de la Defensoría General de la Nación, creada en 2007, pone en marcha tres programas: 1) Programa de Asesoramiento y Representación Legal para personas refugiadas y solicitantes de dicha condición, 2) Programa de patrocinio jurídico gratuito en procesos de ciudadanía iniciados por personas refugiadas y solicitantes de asilo y 3) Programa de asistencia a personas refugiadas y solicitantes del reconocimiento de dicha condición que se encuentran privadas de la libertad. Anteriormente, dicha Comisión centraba su trabajo en los menores de edad para la ley argentina (niños, niñas y adolescentes refugiados y solicitantes de refugio no acompañados o separados de sus familias). De modo que, a partir de 2012, su trabajo se extiende a los adultos.

Aunque concebidos para un público más amplio, en la práctica dichos programas han tenido como principal destinataria a la población que proviene del África subsahariana. En 2008, el $85 \%$ de la población tutelada provenía de esta región. En 2009, ese número se redujo al $66 \%$ debido a una combinación entre un mayor ingreso de colombianos y dominicanos y una disminución en el número de senegaleses, manteniendo igualmente y por mucho el mayor porcentaje ${ }^{20}$. Esta situación se mantiene en períodos subsiguientes. El informe anual de la Comisión para el período 2012 deja ver que, en el marco del Programa de Tutela, Representación Legal y Acompañamiento de los niños, niñas y adolescentes no acompañados o separados de sus familias refugiados y solicitantes del reconocimiento de dicha condición se registra un $91 \%$ de procedentes de África subsahariana, y que esta cifra es del $61 \%$ si se toman los casos atendidos dentro del Programa de Asesoramiento y Representación Legal para personas refugiadas y solicitantes del reconocimiento de dicha condición.

También en 2012, el Área Social de la Comisión Nacional para los Refugiados ${ }^{21}$, creada un año antes, pone en marcha un Programa de Asistencia Humanitaria Básica para asegurar alimentación, salud y alojamiento -y, en el caso de los menores, educación- a la población ligada al sistema de asilo en estado crítico. Es decir, aquellos casos evaluados como "de emergencia":

Un recién llegado que pide refugio y tiene lo puesto. No tiene dónde ir, no tiene qué comer y no conoce a nadie (...) La intención es detectar las problemáticas que se deben abordar para que esa persona de acá a tres meses, seis meses o un año pueda tener una efectiva integración, porque si no es un círculo vicioso y la dependencia de los recursos del Estado va a ser eterna (entrevista a las responsables del Área Social de la CONARE, realizada en agosto de 2013).

Con estas acciones, el Estado asume por primera vez un nuevo tipo de responsabilidad en materia de asilo en lo atinente a cuestiones de integración y acceso a derechos, dispositivos de salud, trabajo, educación, etc., más allá de la elegibilidad de los refugiados. 


\section{Conclusiones}

En este trabajo analizamos la narrativa de identidad nacional dominante en Argentina como una construcción discursiva que se remonta al momento mismo de consolidación del Estado-nación, estrechamente vinculada con factores económico-políticos y motivada por el racismo imperante a nivel mundial en el siglo XIX. Dicha narrativa fue moldeada al calor de dos procesos simultáneos y paralelos: 1) una alterización de la población preexistente y 2) una identificación con Europa, efectuada a través de una activa política estatal de fomento de la inmigración de ese origen. En el caso de los africanos y sus descendientes, su expulsión del mapa identitario nacional se efectuó a partir de un borramiento. En efecto, hemos visto que, si bien el contacto entre África y Argentina ha sido casi permanente desde fines del siglo $\mathrm{XVI}$, el relato oficial no duda en afirmar que en la Argentina no hay negros, cerrando así toda posibilidad de interrogarse acerca del linaje afro local y, más aún, haciendo imposible la pregunta acerca de las manifestaciones de racismo hacia la población de ese origen.

Aunque este cuadro sigue siendo hegemónico, hemos mostrado cómo en los últimos tiempos la narrativa de identidad nacional dominante que atribuye a la Argentina un origen blanco y europeo y sobre la cual pudo montarse el silenciamiento del linaje afro local, presenta signos de revisión y resquebrajamiento. En tal sentido, observamos las características del proceso en curso identificando tres dimensiones. En primer lugar, las acciones de visibilización de temáticas afro que fueron expuestas resumidamente en base a la siguiente clasificación: Lucha contra la discriminación y el racismo, Diagnóstico, Revisiones del pasado, Conmemoraciones y homenajes, Valorización cultural, Promoción de la identidad diaspórica, Acciones afirmativas y de empoderamiento y Educación. En segundo lugar, la gestión y tratamiento de la temática afro en manos de una agencia estatal que se ha erigido como una suerte de especialista en el abordaje de la afroargentinidad: el INADI. Y, en tercer lugar, los espacios y programas que, dentro de la órbita del Estado, diseñan estrategias de inclusión de los migrantes africanos. Es el momento de ponderar el alcance de estos cambios puesto que, aunque no permiten concluir que el paradigma de la invisibilización haya desaparecido por completo, resultan lo suficientemente novedosos como para que reflexionemos acerca de sus consecuencias.

La revisión de iniciativas, agencias y programas realizada muestra un novedoso vínculo local con la africanidad, que solo cobra relevancia y se torna identificable en una comparación con el período anterior. Es a partir de 2005, en el marco del lanzamiento del Plan Nacional contra la Discriminación y del reconocimiento de la población afrodescendiente como uno de los grupos destinatarios de esta política, que se inicia un proceso sostenido de visibilización de las temáticas afro, con repercusiones sobre la población de ese origen. Si bien se registran acciones anteriores en este sentido como las que señalan Gomes (2001) o López (2005), estas han sido puntuales, aisladas entre sí y estuvieron destinadas a (re)crear un sentido de comunidad que interpelaba principalmente a los afroargentinos, no al conjunto de las personas de ascendencia africana y, menos aún, a la sociedad argentina en su totalidad. Aquí radica, a nuestro entender, el principal punto de ruptura.

Los procesos recientes que acabamos de describir, potencialmente reconfiguran la narra- 
tiva de identidad nacional interpelando no solo a las personas que se identifican con una ascendencia africana, sino a la sociedad argentina como un todo. A partir de 2005, cuando el Estado recoge las temáticas afro, las identidades africanas y afrodescendientes se tornan visibles, no solo por volverse objeto sistemático de la gestión estatal (circunstancia inédita por lo demás) sino porque el Estado se convierte en una caja de resonancia de las acciones de la sociedad civil, amplificando su incidencia y capacidad de interpelación social.

La incorporación de estos temas al tratamiento del Estado presenta, no obstante, una línea de corte que distingue entre afroargentinos y africanos. Implícitamente, el Estado identifica como afro solo a los afroargentinos, situación que se evidencia claramente en el trabajo del INADI. En este sentido, cobran relevancia nuevas variables, particularmente importante resulta la de nacionalidad en detrimento de otras como por ejemplo el color de la piel: puesto que buena parte de las acciones de visibilización apuntan a repensar los aportes de los afrodescendientes en la conformación y consolidación de la nación, el discurso del INADI interpela particularmente a los afroargentinos otorgándoles herramientas diferenciales de reivindicación y resarcimiento históricos, no disponibles para otros afrodescendientes o africanos. Sin embargo, la revisión de la narrativa de identidad nacional dominante sienta las bases para establecer un nuevo vínculo con la africanidad, con consecuencias sobre las personas de ascendencia africana no argentinas.

Desde el punto de vista metodológico, este nuevo escenario ofrece una ventaja para el estudio de la presencia africana en Argentina: ya no tener que lidiar con una ausencia. $Y$, al iluminarse la presencia africana, el racismo emerge como un (incipiente) campo de análisis. En efecto, a diferencia de otros contextos nacionales, en Argentina este tema ha sido inexplorado casi por completo. Las razones resultan a esta altura evidentes: en Argentina no habría negros y, por lo tanto, no habría racismo. Los procesos de visibilización actuales repercuten, sin duda, en esta lógica.

Puesto que hemos analizado un proceso aún abierto, las conclusiones de este artículo son (in)conclusiones. Más allá de ello, creemos no equivocarnos cuando decimos que el caso argentino provee a los cientistas sociales un escenario privilegiado para estudiar las formas de inclusión / exclusión que atañen a la población africana y afrodescendiente, los procesos de construcción de la identidad nacional y las dinámicas del racismo. 


\section{Notas}

${ }^{1}$ De más está decir que ese comercio reportó beneficios solamente a Europa y que fue ella, además, la única parte capaz de visualizar el circuito en su totalidad. En el transcurso del siglo XIX, las antiguas zonas de comercio de esclavos pasarán a ser productoras de materias primas en función de los requerimientos europeos. Este es el inicio del llamado comercio legítimo al que muchos antiguos comerciantes de esclavos comenzaron a dedicarse. Así, buena parte de la población esclavizada pasó a destinarse a la producción agrícola dentro del continente, lo que -al decir de Amin (1972)- terminará de bloquear la economía subsahariana. En efecto, Amin discute con las teorías evolucionistas que postulan que las dificultades del "África negra" se deben a que todavía no ha evolucionado lo suficiente postulando, por el contrario, que esa falta de progreso está determinada desde el exterior, es consecuencia de la forma en que la región ha sido integrada a la economía globalizada. "Por consiguiente, esta sociedad 'tradicional' no está en transición (hacia la 'modernidad') sino que es acabada como sociedad dependiente y periférica y, en ese sentido, bloqueada" (p. 18).

${ }^{2}$ En un primer momento, el ingreso de esclavos se dio por la zona del antiguo Tucumán, económicamente conectada con Chile, Paraguay y el Alto Perú, pero hacia la segunda mitad del siglo XVIII comenzó a concentrarse en Buenos Aires. Con respecto a la procedencia se conoce poco. Según Rodríguez Molas (1970) las zonas de extracción de esclavos fueron variando de acuerdo con la época, las compañías y los países que en distintos momentos ejercieron el monopolio del tráfico. Según este historiador, se destaca la región de la costa occidental (Sudán Occidental, la costa de Guinea y el Congo) aunque también se registran ingresos desde Madagascar, especialmente en los últimos años del siglo XVIII. Según Rosal (2011), la falta de precisiones se debe a que las relaciones con África no solían ser directas y a que, en general, solo se consignaba el último puerto de procedencia de cada cargamento aunque, destaca, los compradores tenían interés en conocer el origen de los hombres que adquirían, "pues se tenían clasificadas -obviamente, desde una óptica europea- las distintas virtudes, y también los defectos, de cada uno de los pueblos africanos involucrados: su disposición al trabajo manual o agrícola, y su haraganería; su docilidad y su rebeldía; su afición al alcohol o al robo; los que eran amables y los que sentían inclinación por el arte; los que padecían raptos de melancolía, etcétera" (p. 7).

${ }^{3}$ La colonización portuguesa del archipiélago de Cabo Verde se extiende desde la segunda mitad del siglo XV (el archipiélago, ubicado a $455 \mathrm{~km}$ de la costa africana, fue descubierto por Portugal en el año 1460) hasta el año 1975. En el transcurso del siglo XIX, la economía caboverdeana -débil de por sí-, ya no pudo sostenerse como lo había hecho hasta entonces, es decir, basada en la exportación de productos primarios -principalmente el algodón- $y$ en el comercio de esclavos. Sumado a ello, la industrialización escasa, el clima poco favorable por alternar inundaciones y sequías crónicas y los suelos -escasamente fértiles por estar situados en medio del océano y ser de origen volcánico- agotados, luego de años de una explotación intensiva y sin rotación de cultivos, determinaron el inicio de lo que Maffia (2010) denomina una "diáspora ecológico-económica". La situación fue tan grave que la propia corona portuguesa comenzó a fomentar la emigración hacia otras posesiones lusitanas, pero algunos caboverdeanos se inclinaron por otros destinos y así fue que llegaron a la Argentina.

${ }^{4}$ Maffia (2010) destaca la importancia que fueron adquiriendo las "cartas de llamada" de parientes para ingresar legalmente al país, en un contexto en el que los migrantes "negros provenientes de una colonia portuguesa en África, no estaban entre esas 'migraciones preferibles', sino entre el grupo de las 'no deseables'” (p. 236).

${ }^{5}$ Sobre este punto puede consultarse Blanco (2009). Cabe destacar, igualmente, que los flujos migratorios son mucho mayores al interior del continente africano que hacia fuera. Según Kabunda (2006), "África acoge a unos 40 millones de inmigrantes, en su mayoría africanos, mientras que Europa y Estados Unidos reciben a unos 18 millones de sus ciudadanos". Según datos del Alto Comisionado de las Naciones Unidas para los Refugiados de 2006, África subsahariana acoge el $25 \%$ del volumen total de refugiados mundiales (Muñoz, 2008).

${ }^{6}$ Los senegaleses han recibido la mayor atención, tanto por parte del Estado como por parte de la antropología local. De hecho, ellos mismos han encarado un proceso judicial reclamando al Estado ser protegidos de los acosos policiales reiterados. También han sido objeto de un programa de regularización migratoria focalizado en ellos. Al respecto, puede consultarse: García (2015) y (2016).

${ }^{7}$ De un total de 2.738 residentes africanos registrados en el último censo nacional, 1.737 habitan en Buenos Aires (1.176 en la Ciudad de Buenos Aires -CABA- y 561 en el Gran Buenos Aires -los 24 partidos que rodean a la Ciudad). Fuente: INDEC. Censo Nacional de Población, Hogares y Viviendas 2010.

${ }^{8}$ Gattari (2014) observa cómo en la Provincia de Santa Fe se creó, en 2012, la Asociación Africana de Rosario que nuclea a migrantes africanos de diferentes nacionalidades, todas subsaharianas: ganheses, liberianos, cameruneses, senegaleses, sierraleoneses y marfileños.

${ }^{9}$ Las distintas formas de nucleamiento de raíz afro desde los '90 hasta la actualidad se referencian en García (2016).

${ }^{10} \mathrm{El}$ abordaje del tratamiento hacia el indio excede los límites del presente trabajo. Baste mencionar que la decisión estatal de destruir física y simbólicamente a la población indígena se encuentra sólidamente documentada en los escritos oficiales decimonónicos. Ciertamente, las campañas militares contra el indio no se iniciaron en este período -iniciativas similares tuvieron lugar incluso antes de 1810- pero durante las últimas décadas del siglo XIX, al compás de las políticas de fomento de la inmigración de ultramar, cobraron un nuevo impulso. La ideología racialista imponía un límite a la aceptación de la población indígena en las filas de la civilización. Sin embargo, no todo se jugaba en este terreno. Las campañas contra el indio tenían como objetivo ampliar las fronteras en un momento en que esto traería 
beneficios concretos a quienes pudieran sacar provecho de ello. Lejos de ser reflexiones a posteriori, estos razonamientos pueden leerse en los documentos oficiales de la época. Así por ejemplo, en un mensaje del Poder Ejecutivo al Congreso Nacional del año 1878 (un año antes de iniciarse la "Conquista del Desierto") se solicita extender la ocupación militar hasta el Río Negro en los siguientes términos: "Hasta nuestro propio decoro, como pueblo viril, nos obliga a someter cuanto antes, por la razón o por la fuerza, a un puñado de salvajes que destruyen nuestra principal riqueza y nos impiden ocupar definitivamente, en nombre de la ley del progreso y de nuestra propia seguridad, los territorios más ricos y fértiles de la República" (Auza, 1970, p. 175). Se puede profundizar en estos procesos consultando: García (2014), Lenton (2011) o Trinchero (1998), entre otros.

${ }^{11}$ En 2005, en el marco del lanzamiento de un Plan Nacional contra la Discriminación a través del Decreto presidencial № 1.086, las temáticas afro empiezan a ser tomadas por el Estado. Haciéndose eco de las instancias impulsadas por las organizaciones de la sociedad civil y generando las propias -en forma de campañas, programas, leyes, etc.-, el Estado otorga al tratamiento de "lo afro" una resonancia particular y sostenida en el tiempo. En García (2016) se aborda precisamente este pasaje y se realiza un relevamiento completo de las acciones de visibilización afro hasta 2015.

${ }^{12}$ El Censo Nacional de Población, Hogares y Viviendas 2010 relevó, por primera vez después de más de 100 años, el origen afro en todas sus variantes (descendientes de africanos esclavizados, caboverdeanos y sus descendientes, afrolatinoamericanos e inmigrantes africanos recientes) a través de la siguiente pregunta:

"¿Ud. o alguna persona de este hogar es afrodescendiente o tiene antepasados de origen afrodescendiente o africano (padre, madre, abuelos/as, bisabuelos/as)?" y con las siguientes opciones de respuesta: "Sí" (en ese caso se preguntaba quién) - "No" "Ignorado" (Censo Nacional de Población, Hogares y Viviendas 2010, Cuestionario Ampliado de Viviendas Particulares, pregunta 6). Disponible en: http://www.indec.gov.ar/ftp/cuadros/poblacion/ cuestionario_ampliado_2010.pdf

${ }^{13}$ La fecha conmemora el fallecimiento de María Remedios del Valle, combatiente negra y luchadora por la independencia del país durante la primera parte del siglo XIX.

${ }^{14}$ En adelante, el Instituto Nacional contra la Discriminación, la Xenofobia y el Racismo será referido como INADI.

${ }^{15}$ El INADI fue creado a través de la Ley № 24.515 con el objetivo de garantizar un trato igualitario "a todas aquellas personas cuyos derechos se ven afectados al ser discriminadas por su origen étnico o su nacionalidad, por sus opiniones políticas o sus creencias religiosas, por su género o identidad sexual, por tener alguna discapacidad o enfermedad, por su edad o por su aspecto físico" (extraído de http:// inadi.gob.ar/institucional/ en 2015).

${ }^{16}$ El Decreto № 1.086 o Plan Nacional contra la Discriminación aparece acompañado de otro documento: Hacia un Plan Nacional contra la Discriminación. La discriminación en Argentina. Diagnóstico y propuestas (Anexo de 250 páginas).

${ }^{17}$ Con el transcurso de los años, se abandonó la denominación de "foro" y se empezó a hablar de "programas". Esto responde a la propia historia institucional del organismo y no es necesario (ni posible) profundizar en ello aquí. Baste señalar que, a diferencia del formato anterior, el Programa Afrodescendientes está conformado por representantes de la comunidad afro convertidos en personal contratado del INADI y que, en los hechos, esto se traduce en una dinámica de trabajo más cerrada, menos accesible al colectivo afro en general y más sujeta a la agenda del Estado.

EI INADI cuenta, a su vez, con una línea de trabajo que brinda asistencia telefónica especializada en temas de discriminación. Desde octubre de 2006, a través del 0800-INADI se responden consultas, se realizan derivaciones y se brinda asesoramiento para efectuar denuncias.

${ }^{18}$ Toda persona de origen extranjero que decida establecerse -ya sea temporal o permanentemente- en la Argentina tiene la obligación de tramitar un permiso de residencia, lo que supone establecer contacto con los ámbitos estatales encargados del tema. Esos son los espacios que podríamos denominar "de ingreso obligatorio", contrariamente a los que aquí observaremos que solo son activados por requerimiento del migrante.

${ }^{19}$ La mayor parte de los africanos que ingresan a la Argentina buscan regularizar su residencia a través del sistema de asilo. En muchos casos, esto se explica más por las limitaciones que les ofrece la normativa migratoria local, que por haber sufrido una situación real o potencial de peligro en el país de origen (técnicamente necesaria para apelar al sistema de protección internacional). Un desarrollo completo de estas cuestiones se encuentra en García (2016).

${ }^{20}$ La población dominicana, mayoritariamente femenina, ha compartido -por momentos- espacios de trabajo conjunto con los migrantes senegaleses. Aunque dichos espacios ponían su énfasis en la petición de asilo de los involucrados y no en el color de la piel, este factor no pasa desapercibido. Sobre todo, teniendo en cuenta que los solicitantes de asilo de nacionalidad colombiana (que no necesariamente tienen fenotipos afro) no se han acercado a los mismos.

${ }^{21}$ La Comisión Nacional para los Refugiados (CONARE) es el organismo que se encarga de la elegibilidad de los refugiados en Argentina. Está conformada por un representante del Ministerio del Interior, un representante del Ministerio de Relaciones Exteriores, Comercio Internacional y Culto, un representante del Ministerio de Justicia, Seguridad y Derechos Humanos, un representante del Ministerio de Desarrollo Social y un representante del INADI y, con voz y sin voto, un representante del Alto Comisionado de las Naciones Unidas para los Refugiados -más conocido como ACNUR-y un representante de una organización no gubernamental -hasta el momento, este lugar ha sido ocupado por la Fundación Comisión Católica Argentina de Migraciones, una organización dependiente de la Comisión Episcopal para la Pastoral de Migraciones y Turismo con una larga trayectoria local en materia de atención a migrantes y refugiados que, hasta 2006 y durante varias décadas, implementó los planes de asistencia elaborados por el ACNUR para la Argentina. Aunque el contacto con la CONARE es obligatorio para quienes soliciten ser reconocidos como refugiados, el contacto con el Área Social no lo es. 


\section{Referencias bibliográficas}

Amin, S. (1972). Subdesarrollo y dependencia en África negra. Los orígenes históricos y las formas contemporáneas (Prefacio). En Boubacar, B. Le royaume du Waalo. Le Sénégal avant la conquet coloniale. París: Maspero. (Traducción de María Elena Vela).

Andrews, G. (1990). Los afroargentinos de Buenos Aires. Buenos Aires: Ediciones de la Flor.

Auza, N. (1970). Mensaje del Poder Ejecutivo Nacional pidiendo llevar la ocupación militar hasta Río Negro y Ley № 817 de Inmigración y Colonización. Documentos para la Enseñanza de la Historia Argentina I (1852-1890), Buenos Aires: Pannedille.

Blanco, P. (2009). Polizones africanos en la Argentina. Cuerpo, Subjetividad y Cultura. La experiencia migratoria de los polizones africanos que arriban a la Argentina (2004-2005). (Tesis inédita de maestría). Universidad Nacional Quilmes, Buenos Aires.

Briones, C. (2002). Mestizaje y blanqueamiento como coordenadas de aboriginalidad y nación en Argentina. RUNA, XXIII, pp. 6188. Recuperado de http://www.ram-wan.net/restrepo/identidad/ mestizaje\%20y\%20blanqueamiento-briones.pdf

Comisión para la Asistencia Integral y Protección del Refugiado y Peticionante de Refugio de la Defensoría General de la Nación (2013). Informe Anual para el período noviembre de 2011- noviembre de 2012.

Contarino, L. (2012). La memoria olvidada de la esclavitud y la africanidad: el caso de los inmigrantes caboverdeanos en la Argentina. En Pineau, M. (Ed.) Huellas y legados de la esclavitud en las Américas. Buenos Aires: Eduntref.

Devoto, F. (2003). Historia de la inmigración en la Argentina. Buenos Aires: Sudamericana.

Frigerio, A. (2006). 'Negros' y 'Blancos' en Buenos Aires: repensando nuestras categorías raciales. En Maronese, L. (Ed.), Temas de Patrimonio Cultural 16. Buenos Aires Negra. Identidad y Cultura. CABA: Comisión para la Preservación del Patrimonio Histórico Cultural de la Ciudad de Buenos Aires.

García, M. (2016). Bajo la óptica del Estado. Migrantes senegaleses y procesos de visibilización en Argentina (2005 - 2015). (Tesis de doctorado). Facultad de Filosofía y Letras de la Universidad de Buenos Aires, CABA. Disponible en: http://repositorio.filo.uba.ar/ handle/filodigital/3268

(2015). ¿Qué significa discriminar? Etnografía de la judicialización de la venta ambulante de inmigrantes africanos en la Ciudad de Buenos Aires. Cuadernos de Antropología (11), 2536. Disponible en: http://ppct.caicyt.gov.ar/index.php/cuan/issue/ view/296/showToc

(2014). Los Márgenes de la Nación. Conformación de Estado nacional y construcción de la otredad en la Argentina. En Monsalve, P. \& Cáceres, V. (Ed.), Hacia la Promoción y Protección de los Derechos Económicos, Sociales, Culturales y Ambientales en la Argentina (pp. 71-86). Buenos Aires: Universidad Nacional de General Sarmiento.
Gattari, M. (2014). Migración africana hacia la Argentina. La conformación de la Asociación Africana de Rosario. XI Congreso Argentino de Antropología Social, Universidad Nacional de Rosario, Rosario.

Geler, L. (2010). Andares negros, caminos blancos: afroporteños, Estado y Nación. Argentina a fines del siglo XIX. Rosario: Prohistoria ediciones, TEIAA.

(2006). La sociedad 'de color' se pone de pie. Resistencia, visibilidad y esfera pública en la comunidad afrodescendiente de Buenos Aires, 1880. En Dalla, G., García, P. et al. (Ed.), Homogeneidad, Diferencia y Exclusión en América Latina. Barcelona: Publicacions de la Universitat de Barcelona.

Goldberg, M. (1995). Los negros de Buenos Aires. En Montiel. L. (Ed.), Presencia Africana en Sudamérica (pp. 529-607). México: Consejo Nacional de Cultura y Artes.

Gomes, M. (2001). Apuntes para una historia de las instituciones negras en la Argentina. En Picotti, D. (Ed.), El negro en la Argentina. Presencia y negación. Buenos Aires: Editores de América Latina.

Guzmán, F. (2013). Performatividad social de las (sub)categorías coloniales. Mulatos, pardos, mestizos y criollos en tiempos de cambios, guerra y política, en el interior de la Argentina. En Guzmán, F. \& Geler, L. (Ed.), Cartografías afrolatinoamericanas: perspectivas situadas para análisis transfronterizos. Buenos Aires: Biblos.

(2006). Africanos en la Argentina: una reflexión desprevenida. Andes (17), pp. 197-238. Recuperado de http:// redalyc.org/toc. $.0 a ?$ id $=127$ \&numero $=6117$

Halperin, T. (1987). ¿Para qué la inmigración? Ideología y política inmigratoria en la Argentina (1810-1914). En Halperin Donghi, T. El espejo de la historia. Buenos Aires: Sudamericana.

INADI (2015). Página institucional. Recuperado de http://inadi. gob.ar/institucional/

INDEC (2010). Censo Nacional de Población, Hogares y Viviendas. Recuperado de http://www.indec.gov.ar/

Kabunda, M. (2006). África: migraciones horizontales. Caffe Reggio. Recuperado de http://www.caffereggio.net/2006/05/07/ migraciones-horizontales-de-mbuyi-kabunda-en-el-mundo/

Lenton, D. (Ed.) (2011). Dossier: Genocidio y política indigenista: debates sobre la potencia explicativa de una categoría polémica. Corpus, Archivos Virtuales de la Alteridad Americana, 1 (2).

Lévi-Strauss, C. (1976). Tristes Trópicos. Buenos Aires: Eudeba. López, L. (2005). “'Hay alguna persona en este Hogar que sea Afrodescendiente?". Negociaçoes e disputas políticas em torno das classificaçoes étnicas na Argentina. (Tesis inédita de Maestría). Universidad Federal do Rio Grande do Sul, Porto Alegre.

Maffia, M. (2010). Desde Cabo Verde a la Argentina. Migración, parentesco y familia. Buenos Aires: Biblos.

Maffia, M. \& Ceirano, V. (2007). Estrategias políticas y de reconocimiento en la comunidad caboverdeana de Argentina. Contra Relatos desde el Sur. Apuntes sobre África y Medio Oriente, 3 (4), 
81-107. Recuperado de http://biblioteca.clacso.edu.ar/Argentina/ cea-unc/20110420090644/conrarelatos.pdf

Marcelino, P. \& Cerrutti, M. (2011). Recent African immigration to South America: the cases of Argentina and Brasil in the regional context. Informe presentado ante el Centro Latinoamericano y Caribeño de Demografía, División de Población de la CEPAL. Recuperado de http://www.cepal.org

Mitullah, W. (2003). Street vending in african cities: a synthesis of empirical findings from Kenya, Cote d'Ivoire, Ghana, Zimbabwe, Uganda and South Africa. Background Paper for the 2005 World Development Report. Recuperado de http://siteresources. worldbank.org/INTWDRS/Resources/477365-1327693758977/ BP_Streetvending_African_Cities.pdf

Morini, R. (2001). Los otros desaparecidos argentinos: Africanos de Buenos Aires $33 \%$ de la población en 1810. El Corresponsal. Recuperado de http://www.elcorreo.eu.org/esp/article.php3?id_ article $=2713$

Muñoz, C. (2008). Refugiados en América Latina. Le Monde diplomatique. Edición Argentina.

Otero, N. (2000). Afroargentinos y caboverdeanos. Las luchas identitarias contra la invisibilidad de la negritud en Argentina. (Tesis inédita de maestría). Universidad Nacional de Misiones, Misiones.
Plan Nacional contra la Discriminación (Decreto $\mathrm{N}^{\circ}$ 1.086) y su Anexo: Hacia un Plan Nacional contra la Discriminación. La discriminación en Argentina. Diagnóstico y propuestas (2005). Año CXIII, № 30.747. CABA: Boletín Oficial de la República Argentina.

Rodríguez, R. (1970). El negro en el Río de la Plata. Historia Integral Argentina, Tomo V: De la Independencia a la Anarquía, Buenos Aires: Centro Editor de América Latina.

(1962). El negro en el Río de la Plata. Historia Integral Argentina, Tomo V: De la Independencia a la Anarquía, Buenos Aires: Centro Editor de América Latina.

Rosal, M. (2011). Africanos esclavizados llegados al Plata durante el lapso tardocolonial. Afrodescendencia. Aproximaciones contemporáneas de América Latina y el Caribe. Centro de Información de las Naciones Unidas para México, Cuba y República Dominicana. Recuperado de http://www.cinu.mx/noticias/AFRODESCENDENCIA.pdf

Tonello M. (1992). Sarmiento, los inmigrantes y la nacionalidad argentina. Revista del Departamento de Historia de la Universidad Nacional de Tucumán, 2 (2), 3-20.

Trinchero, H. (1998). Desiertos de identidad. Papeles de trabajo (7) 85-129.

Villavicencio, S. (2003). Ciudadanos para una nación. En Villavicencio, S. (Ed.), Los Contornos de la Ciudadanía. Nacionales y extranjeros en la Argentina del centenario. Buenos Aires: Eudeba. 